\title{
BH3 mimetics efficiently induce apoptosis in mouse basophils and mast cells
}

\author{
Ramona Reinhart ${ }^{1}$, Lionel Rohner ${ }^{2}$, Simone Wicki ${ }^{1}$, Michaela Fux ${ }^{2}$ and Thomas Kaufmann ${ }^{\star, 1}$
}

Basophil granulocytes and mast cells are recognized for their roles in immunity and are central effectors of diverse immunological disorders. Despite their similarities, there is emerging evidence for non-redundant roles of the circulating yet scarce basophils and tissue-resident mast cells, respectively. Because of their importance in allergic pathogenesis, specific induction of apoptosis in basophils and mast cells may represent an interesting novel treatment strategy. The pro-inflammatory cytokine interleukin-3 serves as a key factor for basophil and mouse mast cell survival. Interleukin-3 increases the expression of anti-apoptotic BCL-2 family members, such as BCL-2, BCL- $\mathrm{X}_{\mathrm{L}}$ or MCL-1; however, little is known how strongly these individual proteins contribute to basophil survival. Here, we were applying small molecule inhibitors called BH3 mimetics, some of which show remarkable success in cancer treatments, to neutralize the function of anti-apoptotic BCL-2 family members. We observed that expression levels of anti-apoptotic BCL-2 proteins do not necessarily correlate with their respective importance for basophil survival. Whereas naive in vitro-differentiated mouse basophils efficiently died upon BCL-2 or BCL- $X_{L}$ inhibition, interleukin-3 priming rendered the cells highly resistant toward apoptosis, and this could only be overcome upon combined targeting of BCL-2 and BCL- $\mathrm{K}_{\mathrm{L}}$. Of note, human basophils differed from mouse basophils as they depended on BCL-2 and MCL-1, but not on BCL- $\mathrm{X}_{\mathrm{L}}$, for their survival at steady state. On the other hand, and in contrast to mouse basophils, MCL-1 proved critical in mediating survival of interleukin-3 stimulated mouse mast cells, whereas BCL- $\mathrm{X}_{\mathrm{L}}$ seemed dispensable. Taken together, our results indicate that by choosing the right combination of BH3 mimetic compounds, basophils and mast cells can be efficiently killed, even after stimulation with potent prosurvival cytokines such as interleukin-3. Because of the tolerable side effects of BH3 mimetics, targeting basophils or mast cells for apoptosis opens interesting possibilities for novel treatment approaches.

Cell Death and Differentiation (2018) 25, 204-216; doi:10.1038/cdd.2017.154; published online 29 September 2017

Together with neutrophils and eosinophils, basophils belong to the granulocyte fraction of circulating blood leukocytes that are recruited to sites of infection. ${ }^{1}$ Even though basophils constitute $<1 \%$ of circulating leukocytes, they were recognized for their pivotal functions in immunity. Besides their essential effector function during helminth infections, ${ }^{2,3}$ basophils have a prominent role in the acquired, antibodymediated immunity against ticks. ${ }^{4}$ Importantly, basophils also contribute to a variety of immunological disorders, including non-redundant key roles in immunoglobulin $\mathrm{G}(\mathrm{IgG})$-mediated, but not IgE-mediated, systemic anaphylaxis in mice ${ }^{5}$ and critical regulatory and effector functions in immediate, latephase and a form of delayed hypersensitivity reaction described as cutaneous basophil hypersensitivity. ${ }^{6-9}$

Basophils share several key features with mast cells, even though the latter are tissue-resident. Basophils and mast cells are closely related in the mouse as they develop from a common precursor ${ }^{10}$ and, importantly, both cell types express the high-affinity receptor for $\operatorname{lgE}, \mathrm{FccRI}$, on their surfaces. Moreover, both cell types contain granules of similar content, including $\mathrm{T}_{\mathrm{H}}$ 2-associated cytokines such as IL-4 and IL-13, preformed mediators, like proteases, proteoglycans and histamine, as well as de novo synthesized lipid mediators. ${ }^{11}$ Despite these similar features and certain overlapping functions, there is increasing evidence that basophils and mast cells do also exert important non-redundant roles (reviewed in Karasuyama et al. ${ }^{12}$ and Galli $^{13}$ ). Of note, mouse basophils differ in several aspects from human basophils, but still functionally correspond to each other. ${ }^{14}$

Numerous previous studies have demonstrated that IL-3 is a critical cytokine for basophil and mast cell differentiation and survival. ${ }^{15,16}$ However, in contrast to basophils, IL-3 drives ex vivo differentiation of mouse, but not human, mast cells. ${ }^{17}$ As seen in human basophils, IL-3 upregulates the protein expression of anti-apoptotic MCL-1, BCL- $\mathrm{X}_{\mathrm{L}}, \mathrm{BCL}-2$ and clAP2, ${ }^{18,19}$ and protects basophils not only from intrinsic apoptotic stresses ${ }^{18}$ but also from TRAIL-, IFNa- or FasL-mediated apoptosis. ${ }^{19}$ However, even though several anti-apoptotic BCL-2 family members were shown to be upregulated in basophils upon IL-3 stimulation, their distinct and specific functional impact on basophil viability remains to be investigated. To address the question of how importantly individual pro-survival proteins contribute to basophil survival and whether this regulation is distinct from mast cell survival, we took advantage of a newly developed class of small molecule compounds, called $\mathrm{BH} 3$ mimetics. BH3 mimetics act as inhibitors of anti-apoptotic BCL-2 family members by interfering with protein-protein interactions. Because of the

${ }^{1}$ Institute of Pharmacology, University of Bern, Bern, Switzerland and ${ }^{2}$ University Institute of Clinical Chemistry, University of Bern, Bern, Switzerland

${ }^{*}$ Corresponding author: T Kaufmann, Institute of Pharmacology, University of Bern, Inselspital INO-F, Office 56.F-603, Bern 3010, Switzerland. Tel: +41 31 632 3289 ; Fax: +41 3163249 92; E-mail: thomas.kaufmann@ pki.unibe.ch

Received 12.5.17; revised 28.7.17; accepted 11.8.17; Edited by R De Maria; published online 29.9.17 
improvement of their chemical structure and properties, $\mathrm{BH} 3$ mimetics are now available to specifically target individual family members, including $B C L-2,{ }^{20} \quad B C L-X_{L}^{21,22}$ and MCL-1. ${ }^{23-25}$ The BCL-2 selective drug ABT-199 (Venetoclax) has recently been approved for the use in aggressive forms of chronic lymphocytic leukemia (CLL) due to its high efficacy and tolerable side effects. ${ }^{26}$ Even though $\mathrm{BH} 3$ mimetics were developed as anti-cancer therapeutics, it is conceivable to speculate that they may be useful to eliminate activated immune cells implicated with certain immunological disorders. In this study, functional testing of $\mathrm{BH} 3$ mimetics could not only reveal the importance of the distinct anti-apoptotic BCL-2 family members for basophil and mast cell survival, but also indicate that anti-apoptotic BCL-2 proteins may represent molecular targets in activated basophils or mast cells to overcome IL-3-induced survival enhancement, for example, in allergic disorders.

\section{Results}

IL-3 induces anti-apoptotic BCL-2 family members, while $\mathrm{BH} 3$ mimetics promote caspase-3 processing in mouse basophils. We performed qPCR array analysis in IL-3 ${ }^{\text {cond }}$ Hoxb8 basophils originating from conditionally immortalized mouse bone marrow progenitors ${ }^{27,28}$ (further referred to as in vitro-differentiated mouse basophils) to study the impact of IL-3 on genes regulating apoptosis. As shown in Figure 1, IL-3 increased pro-survival genes such as $\mathrm{Bcl}-2$, $B C l-x_{L}$ and $M c l-1$ in mouse basophils, while pro-apoptotic genes like caspase-2, -3, -9 and Bim were downregulated (see Supplementary Table S1 for full array list). We focused on pro-survival members of the BCL-2 family, as they likely account for the IL-3-mediated pro-survival effects. We first validated the IL-3-induced increase in mRNA levels of $\mathrm{Bcl}-2$, $\mathrm{Mcl}-1$ and $\mathrm{Bcl}-x_{L}$ by $\mathrm{qPCR}$ using independent primer sets (Figure 2a). Moreover, IL-3 reduced the transcription of the pro-apoptotic $\mathrm{BH} 3$ only gene Puma, while Bim levels remained unaffected (Figure 2a). Similar to human basophils, $^{18}$ in vitro-differentiated mouse basophils expressed readily detectable protein levels of $M C L-1$, BCL-2 and BCL- $X_{L}$ at steady state, which further increased upon administration of a high concentration of IL-3 $(10 \mathrm{ng} / \mathrm{ml})$, whereas the amount of processed caspase-3 (formation of the active p17 large subunit) strongly decreased in the presence of IL-3 (Figures $2 \mathrm{~b}$ and $\mathrm{c}$, and Supplementary Figure S1). These results largely concur with IL-3-mediated pro-survival effects reported in human primary basophils, ${ }^{18,19}$ supporting that the IL-3-driven signaling pathways in in vitrodifferentiated mouse basophils are comparable to human basophils.

Taking advantage of $\mathrm{BH} 3$ mimetic compounds, which inhibit the pro-survival activities of MCL-1 (A-1210477 $\left.{ }^{29}\right), B C L-2$ (ABT-199/Venetoclax $\left.{ }^{20}\right)$, BCL-X $\left(\mathrm{WEHI}-539^{22}\right)$, or both BCL-2 and BCL- $X_{L}$ (ABT-263/Navitoclax $\left.{ }^{21}\right)$, we investigated the importance of those distinct pro-survival proteins for mouse basophil viability. As shown in Figures $2 b$ and $d$, treatment with the individual $\mathrm{BH} 3$ mimetics all strongly induced the formation of the active caspase-3 p17 large subunit, which was reduced upon co-administration of IL-3. This decrease in caspase-3 processing was partially overcome by blocking of $\mathrm{BCL}-\mathrm{X}_{\mathrm{L}}$, whereas single antagonism of $\mathrm{BCL}-2$ or $\mathrm{MCL}-1$ only had minor effects (Figures $2 b$ and d). Importantly, however,

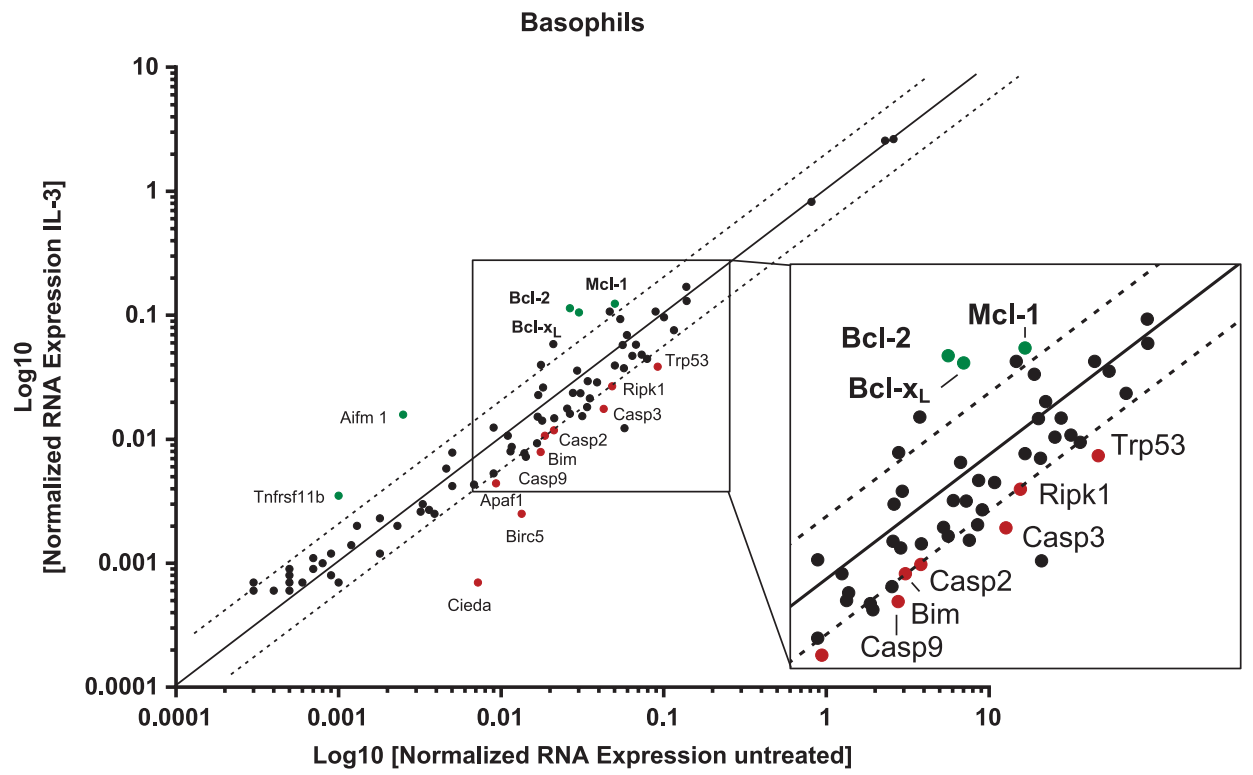

Figure 1 IL-3 induces pro-survival BCL-2 family genes, while pro-apoptotic genes are decreased in mouse basophils. PCR array for genes regulated in apoptotic pathways. In vitro-differentiated mouse basophils were kept either under cytokine-omitted or IL-3 (10 ng/ml)-exposed conditions for $2 \mathrm{~h}$. Using the SA Biosciences software, Ct values were normalized to the average of five different housekeeping genes ( $\beta$ actin, $\beta 2$ microglobulin, Gapdh, Gusb and Hsp90ab1) and linearized with the standard formula for qPCR $\left(2^{-}\left(\mathrm{Ct}^{\text {sample }}-\mathrm{Ct}^{\text {control }}\right)\right)$. While the $y$ axis displays the expression of IL-3-treated cells, the $x$ axis shows corresponding levels of untreated cells. Continuous line matches the expression upon IL-3 with the expression of untreated, while dotted lines display a threshold of twofold increase/decrease of the mRNA expression comparing IL-3 over untreated. See complete gene list in Supplementary Table S1 
b

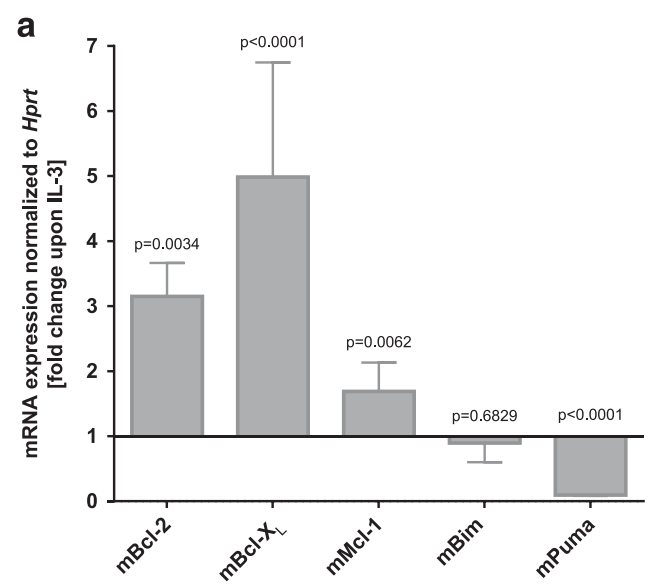

C

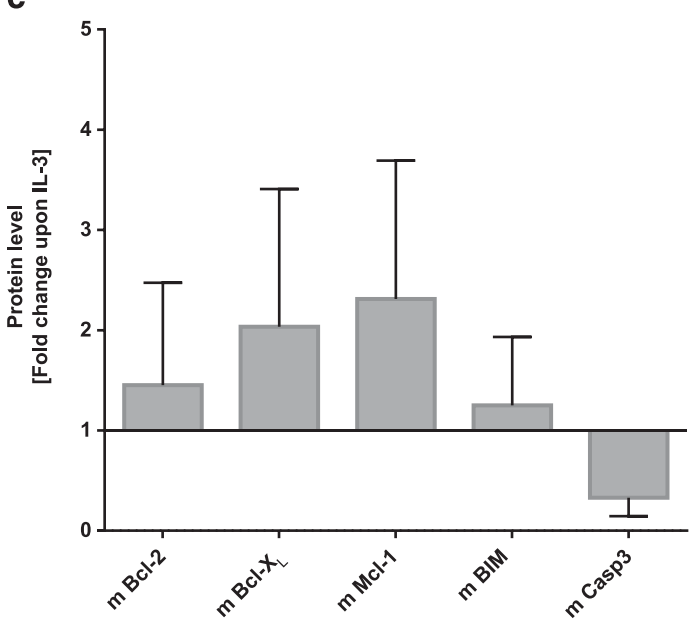

d
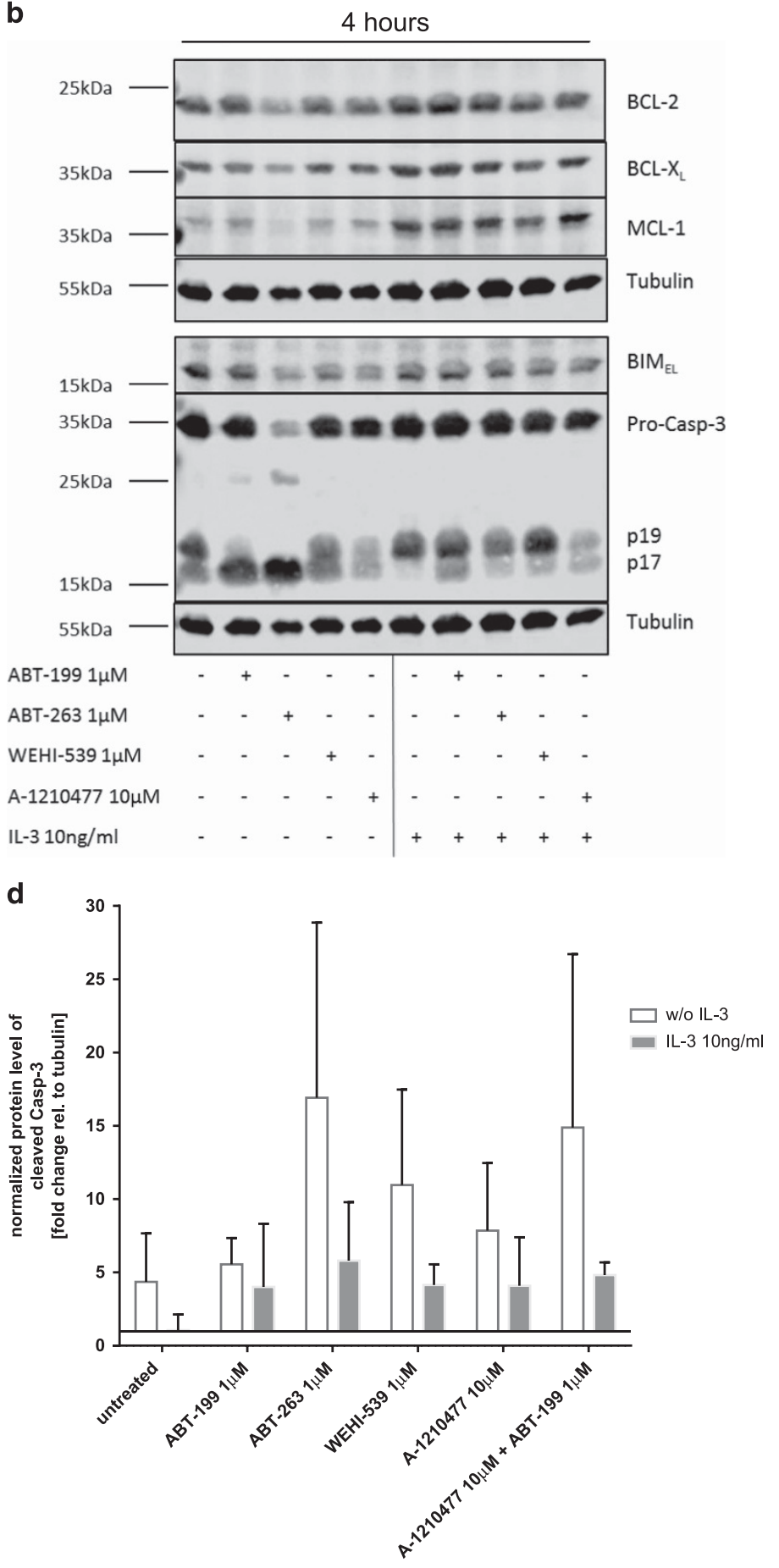

Figure 2 Regulation of pro- and anti-apoptotic proteins by IL-3, and effects of BH3 mimetics, in mouse basophils. (a) qPCR analysis depicting fold change of the mRNA expression in in vitro-differentiated basophils upon IL-3 treatment compared to untreated after $2 \mathrm{~h}$ of incubation; data represent means \pm S.D., $n=6$. Statistical analysis by unpaired $t$-test with post hoc Holm-Sidak multiple comparison correction. (b) Protein levels of in vitro-differentiated basophils after $4 \mathrm{~h}$ of incubation with different $\mathrm{BH} 3 \mathrm{mimetics}$ at indicated concentrations with or without IL-3 $(10 \mathrm{ng} / \mathrm{ml})$, shown by a representative quantitative western blot using near-infrared fluorescence $(n \geqslant 3)$. (c) Quantitative analysis of western blot as shown in (b) normalized to tubulin, displaying fold change of the protein level of BCL-2, BCL-X, MCL-1, BIM and processed caspase-3 (p17 active large subunit) upon IL-3 over untreated; data represent means \pm S.D., $n=5$. (d) Quantified protein levels of active caspase-3 17 large subunit as fold change relative to tubulin expression upon BH3 mimetics treatment alone (white bar) or combined with $10 \mathrm{ng} / \mathrm{ml} \mathrm{IL-3} \mathrm{stimulation} \mathrm{(gray} \mathrm{bar);} n \geqslant 2$, means \pm S.D. 
IL-3
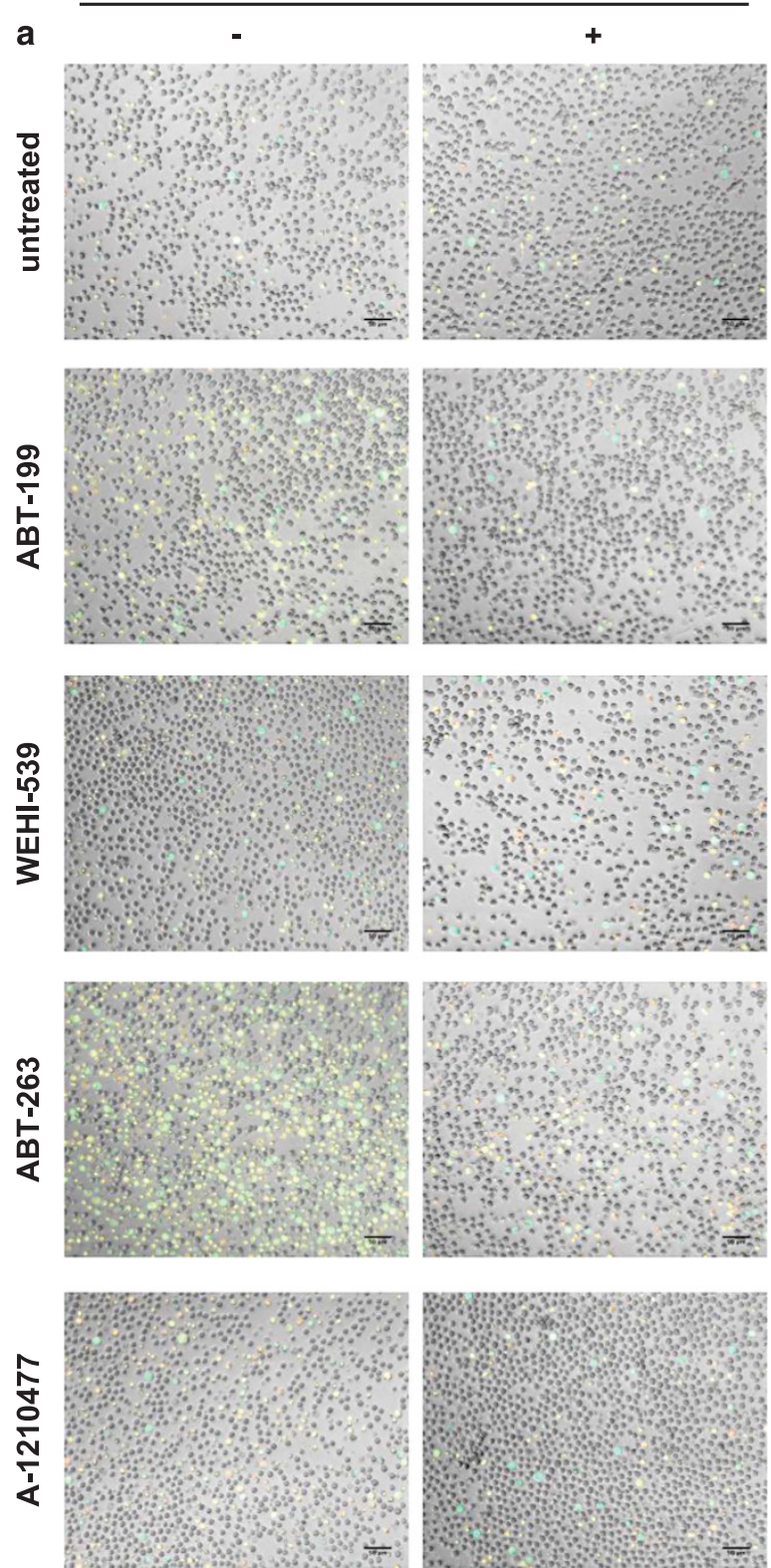

b

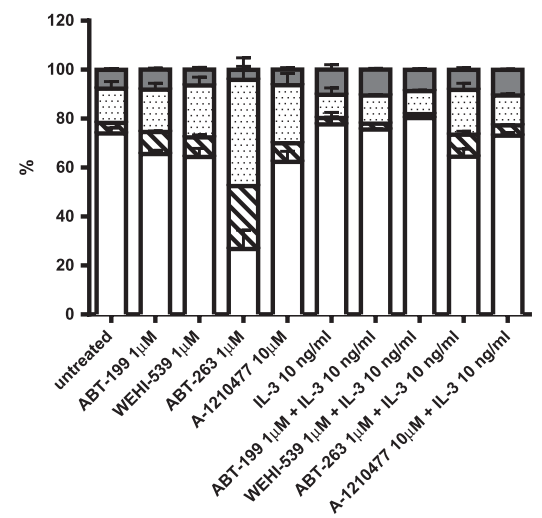

Figure 3 For caption see page on 208
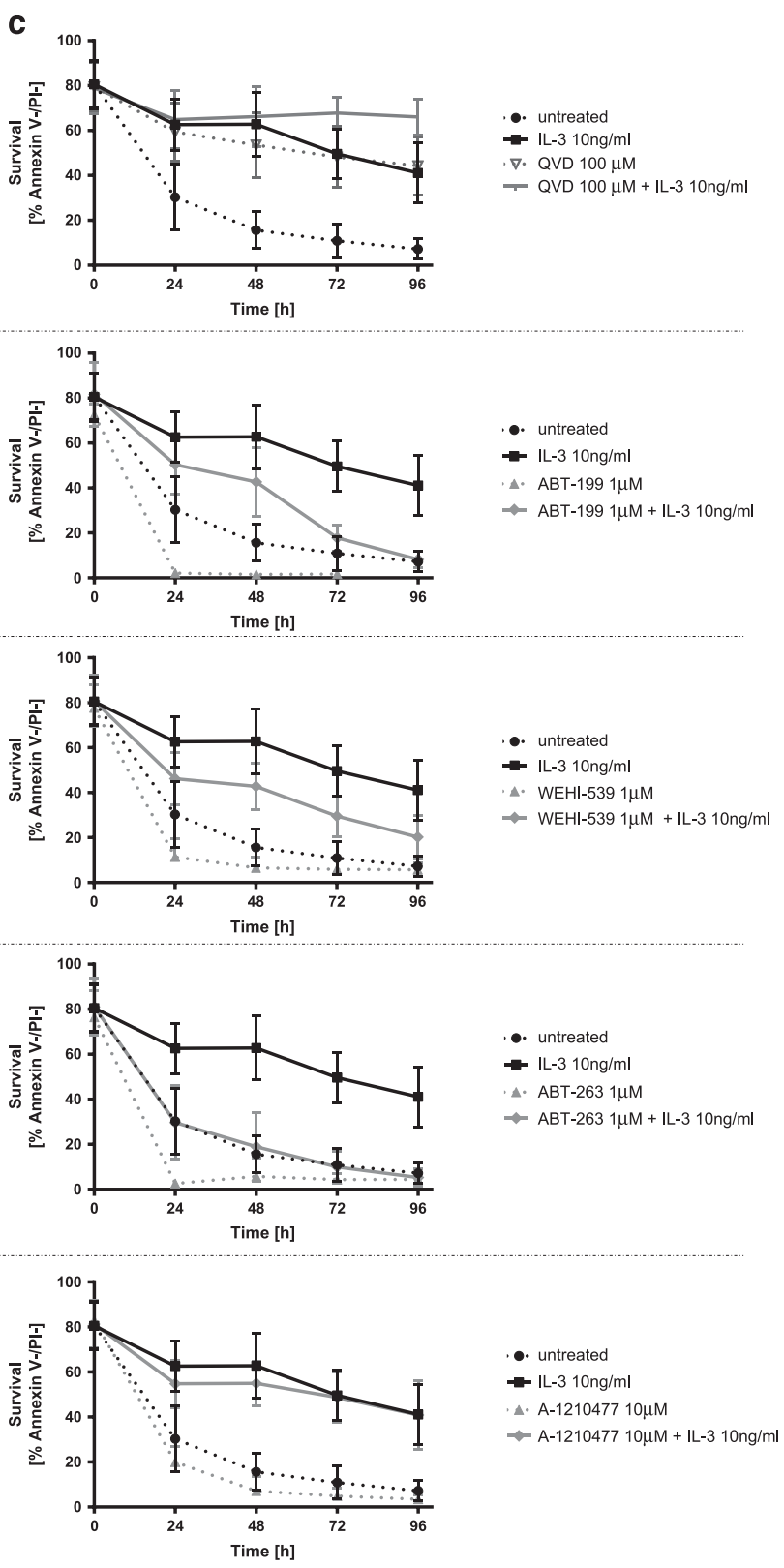

$$
\begin{aligned}
& \square \text { Casp3-/PI+ } \\
& \text { (س) Casp3+/PI+ } \\
& \square \text { Casp3+/PI- } \\
& \square \text { Casp3-/PI- }
\end{aligned}
$$


Figure 3 Viability of mouse basophils highly depends on BCL-2 and BCL-X while MCL-1 is dispensable. (a) Detection of enzymatically active caspase-3 (green) and loss of plasma membrane integrity (PI staining, orange) in in vitro-differentiated basophils after $6 \mathrm{~h}$ of treatment with indicated BH3 mimetics, with and without IL-3, measured by CellEvent assay and subsequent analysis by fluorescence microscopy. One randomly selected picture from at least two independent experiments is shown. (b) Quantitative analysis of caspase-3 activity and PI positivity by flow cytometric measurement of the same samples visualized in (a) (see statistical analysis in Supplementary Table S2). (c) Kinetic viability measurement (GFP-Annexin V/PI exclusion) of in vitro-differentiated basophils in IL-3-free or IL-3 enriched medium treated with various BH3 mimetics at indicated concentrations and time points by flow cytometry; $n \geqslant 5$, (except $n \geqslant 3$ for WEHI-539), data represent means \pm S.D.

combined targeting of BCL-2 and BCL- $\mathrm{X}_{\mathrm{L}}(\mathrm{ABT}-263)$ or $\mathrm{BCL}-2$ and MCL-1 (ABT-199+A-1210477) could fully overcome IL-3mediated protection, inducing strong caspase-3 processing already as early as $4 \mathrm{~h}$ after stimulation (Figures $2 \mathrm{~b}$ and $\mathrm{d}$ ). Those results suggest that the simultaneous inhibition of BCL-2 and BCL- $X_{L}$ can effectively induce activation of apoptotic effector caspases and that this may overcome IL-3-mediated mouse basophil survival.

The combined inhibition of BCL-2 and BCL- $X_{L}$ fully neutralizes IL-3-mediated pro-survival effects in mouse basophils over time. Using a caspase- 3 activity assay, we formally proved that the observed increase of the caspase-3 p17 subunit on immunoblots correlates with increased enzymatic activity (Figure 3a). Quantification of these data by flow cytometry further underlined that ABT-263 could significantly increase caspase- 3 activity and loss of cell membrane integrity compared to the other $\mathrm{BH} 3$ mimetics, both in the absence or presence of IL-3 (Figure 3b, and corresponding statistics in Supplementary Table S2).

Quantification of cellular viabilities (GFP-Annexin V/PI exclusion) over time showed that the spontaneous cell death of in vitro-differentiated mouse basophils was strongly delayed upon addition of high IL-3 concentrations and fully blocked by the pan-caspase inhibitor Q-VD-Oph, indicating that the cells died by classical apoptosis (Figure 3c, and Supplementary Figure S2). We next treated mouse basophils with $\mathrm{BH} 3$ mimetics to evaluate their long-term effects on survival. As shown in Figure 3c, single targeting of $B C L-2$ or $B C L-X_{L}$ further reduced the viability of basophils in the absence of cytokine, with nearly all cells being dead after $24 \mathrm{~h}(P<0.0001$ at $24 \mathrm{~h}$ for both ABT-199 and ABT-263, two-way ANOVA and Sidak's correction, compared to untreated), while targeting of MCL-1 had only a minor effect over untreated control $(P=0.0078$ at $24 \mathrm{~h}$, all other time points NS, two-way ANOVA and Sidak's correction). Interestingly, whereas single inhibition of BCL-2 or BCL- $X_{L}$ could partially counteract the IL-3-induced pro-survival effects $(P$-values for $24 \mathrm{~h} / 48 \mathrm{~h} / 72 \mathrm{~h} / 96 \mathrm{~h}$ : ABT-199, $\mathrm{NS} / 0.0021 /<0.0001 /<0.0001 ;$ WEHI-539, 0.0044/0.0002/ $<0.0001 /<0.0001$, two-way ANOVA and post hoc Sidak's correction for multiple comparison, compared to IL-3 alone), blocking MCL-1 with A-1210477 had no such effect (Figure 3c). Of note, when BCL-2 and BCL- $X_{L}$ were simultaneously blocked by ABT-263, the IL-3-mediated survival benefit was completely abolished (Figure 3c, $P$-value $<0.0001$ for all time points, two-way ANOVA and post hoc Sidak's correction for multiple comparison over IL-3 alone). In summary, these data suggest that, over time, the individual targeting of $\mathrm{BCL}-2$ and $\mathrm{BCL}-\mathrm{X}_{\mathrm{L}}$ is only partially able to overcome IL-3-mediated basophil survival, while the combined targeting fully abrogates it. Furthermore, even though MCL- 1 is upregulated by IL-3, inhibition of MCL- 1 alone is insufficient to counteract the IL-3-mediated pro-survival effects.

BCL-2 and MCL-1 are required to maintain viability of human primary basophils. Similar to mouse basophils, we identified BCL-2 as a critical protein maintaining the steady state survival of human basophils, whereas - in contrast to mouse basophils - we found that blocking MCL-1 significantly decreased human basophil viability, while blocking of BCL- $\mathrm{X}_{\mathrm{L}}$ had no such effect (Figure $4 a$ and Supplementary Figure S3). Cell death could be blocked by the pan-caspase inhibitor Q-VD-Oph, demonstrating that classical apoptosis was the underlying mechanism (Figure 4a). Treating human primary basophils with the different BH3 mimetics decreased BCL-2 and MCL-1 protein levels, correlating with an increase in caspase-3 activity (Figures $4 \mathrm{~b}$ and $\mathrm{c}$, and statistics in Supplementary Table S3). Taken together, we could reveal that BCL-2 and MCL-1 have an independent key role in maintaining the viability of human primary basophils, while, in contrast to mouse basophils, BCL- $X_{L}$ seems to be dispensable.

BCL-2 and MCL-1 are important in maintaining mouse mast cell viability. To investigate whether anti-apoptotic BCL-2 family members regulate basophil or mast cell survival differently, we next investigated the effects of IL-3 and the killing potential of $\mathrm{BH} 3$ mimetics on mouse mast cells, using the well-accepted in vitro-differentiation protocol from bone marrow. ${ }^{30}$ Bone marrow-derived mast cells (BMMC) were differentiated in IL-3 enriched medium for at least 4 weeks, resulting in a c-kit ${ }^{+} \mathrm{FccRl}{ }^{+}$population of high purity (Supplementary Figure S4).

qPCR array analysis showed that IL-3 increases prosurvival genes such as $B c /-2$ and $B c l-x_{L}$, while pro-apoptotic genes like caspase-3, Bad and Bim were downregulated (Figure 5a, and Supplementary Table S1 for full array list). Validation with independent primer sets confirmed that, similar to mouse basophils, IL-3 transcriptionally induced the mRNA expression of $\mathrm{Bcl}-2, \mathrm{Bcl}-x_{L}(P$-values $0.0036 / 0.0054)$ and $\mathrm{Mcl}-$ 1 (NS), while Puma was downregulated (Figure 5b). Addition of high concentration of IL-3 increased MCL-1 protein levels, but less so BCL-2 and BCL- $X_{L}$ levels (Figures $5 c$ and $d$ ), decreased caspase-3 activity, spontaneous mast cell apoptosis and significantly counteracted $\mathrm{BH} 3$ mimetics-induced apoptosis (Figures $6 \mathrm{a}-\mathrm{c}$ ). The most pronounced induction of BMMC cell death at early time points could be seen upon the inhibition of either MCL-1, BCL-2 or the combined inhibition of $B C L-X_{L}$ with $B C L-2$. However, only the latter could significantly overcome the IL-3-induced pro-survival effect already after $6 \mathrm{~h}$ (Figure 6b, two-way ANOVA, Turkey's multiple comparisons test, $P$-value $=0.0007$ ). 

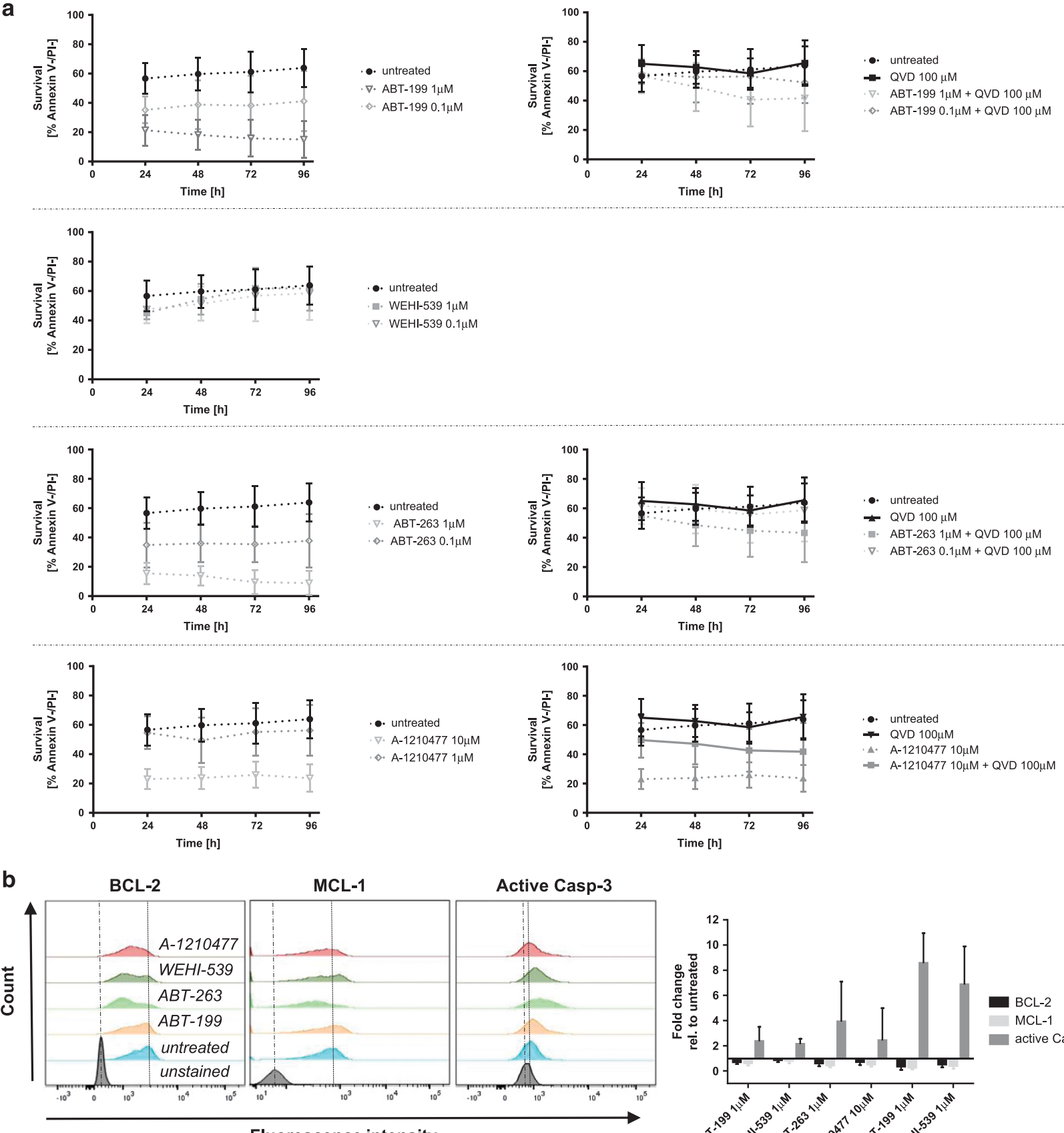

Fluorescence intensity
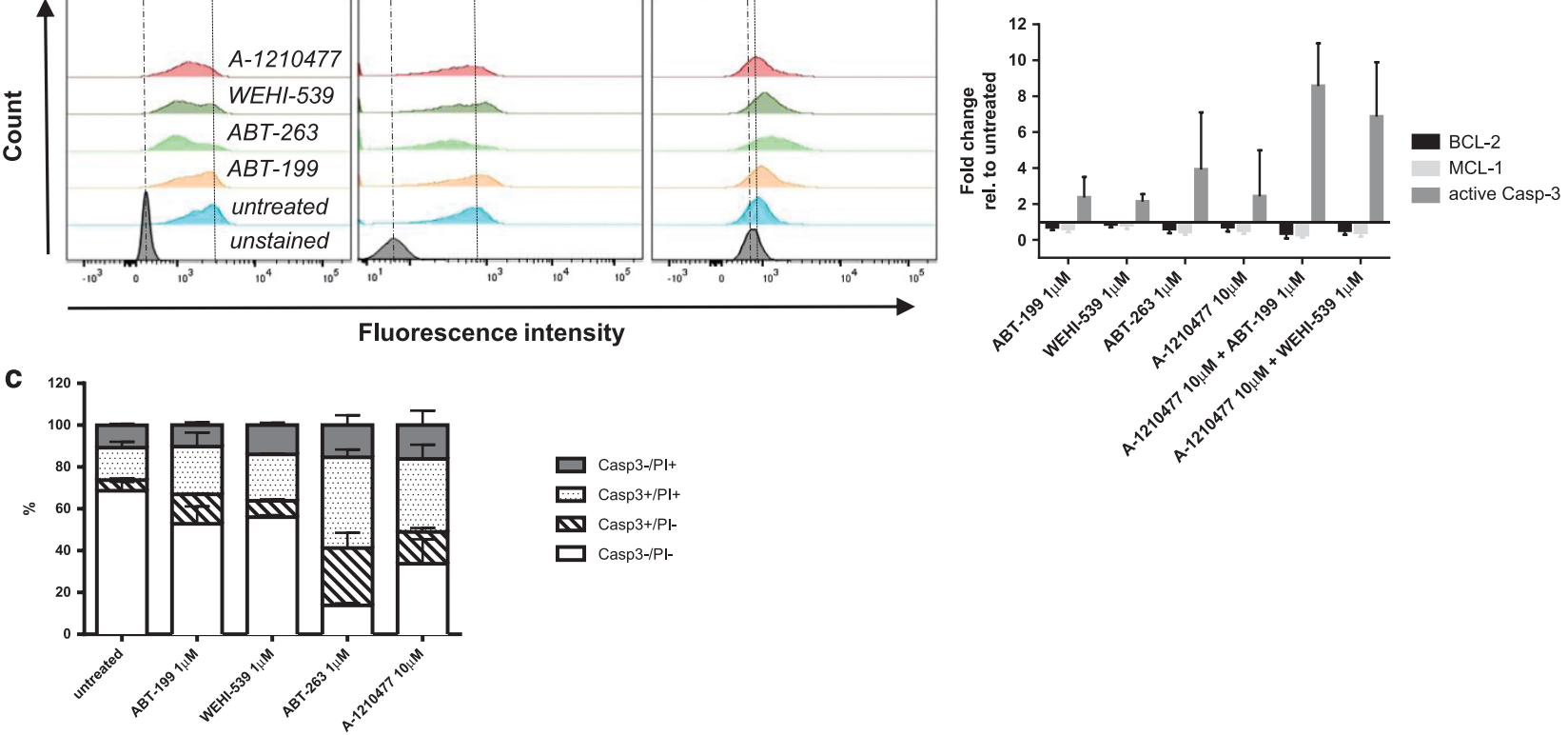

Figure 4 For caption see page on 210 
Figure 4 Human primary basophils critically depend on BCL-2 and MCL-1 for their survival. (a) Flow cytometric analysis of human basophil viability (GFP-Annexin V/PI exclusion) over time upon treatment with $\mathrm{BH} 3$ mimetics at indicated concentrations. Induced cell death was blocked by co-incubation with the pan-caspase inhibitor Q-VD-Oph $(100 \mu \mathrm{M}) ; n \geqslant 4$, means \pm S.D. (b) Intracellular staining (IC) of BCL-2 (clone 100), MCL-1 (clone Y37) and active caspase-3 (clone D3E9) protein levels in human basophils treated for $4 \mathrm{~h}$ with different $\mathrm{BH} 3$ mimetic compounds ( $1 \mu \mathrm{M}$ ABT-199, $1 \mu \mathrm{M}$ ABT-263, $1 \mu \mathrm{M}$ WEHI-539, $10 \mu \mathrm{M} \mathrm{A}-1210477$ or combinational treatments) measured by flow cytometry; representative histograms of fluorescence intensity shown $(n=4)$. Quantitative evaluation of IC staining of BCL-2, MCL-1 and active caspase-3 protein levels as fold change upon BH3 mimetic treatment over untreated; $n=4$, means \pm S.D. (c) Quantitative analysis of CellEvent assay measuring protease activity of caspase-3 and PI positivity by flow cytometry after $24 \mathrm{~h}$ of incubation using the same concentrations of $\mathrm{BH} 3$ mimetics as in (b); $n=4$, means \pm S.D.; see Supplementary Table S3 for statistical analysis

At later time points, a critical role for $\mathrm{BCL}-2$ in maintaining BMMC viability could be confirmed, as single treatment with ABT-199 markedly reduced viability in the absence of IL-3 and partially, but significantly, counteracted the pro-survival effects of IL-3 (Figure 6c, two-way ANOVA, Sidak's multiple comparisons test; $P$-value $<0.0001$ for all time points). Not surprisingly, similar results were obtained with ABT-263 single treatments ( $P$-value $<0.0001$ for all time points). In contrast, however, BCL- $X_{L}$ inhibition only showed minor effects on BMMC viability, indicating that - especially in the presence of IL-3 - the anti-apoptotic function of BCL- $X_{L}$ is either less important in BMMCs or might be compensated by other family members. Moreover, and in contrast to mouse basophils, we revealed an important role of $\mathrm{MCL}-1$ for the survival of mouse BMMC (Figure 6c, $P$-value $<0.0001$ for all time points with $10 \mu \mathrm{M} \mathrm{A}-1210477 \mathrm{in}$ the presence of IL-3 and for $24 \mathrm{~h}$ and $48 \mathrm{~h}$ time points in the absence of IL-3). These results show that BCL-2 as well as MCL-1 have pivotal roles in cell death regulation of $\mathrm{BMMC}$.

\section{Discussion}

The pro-inflammatory cytokine IL-3 is known to inhibit apoptosis in many cells, including basophils ${ }^{18}$ and mouse mast cells, ${ }^{31}$ both of which are important effector cells in allergic diseases in which IL-3 is released from allergic tissue. $^{32}$ Importantly, non-redundant roles of basophils in allergic inflammation are emerging, which in turn may also involve chronicity. ${ }^{33}$ To enable new treatment possibilities in diseases correlating with basophil or mast cell hyperreactivity, a better understanding of their distinct cell survival regulation is needed.

With this study, we could reinforce that, besides its role in basophil and mouse mast cell development and differentiation, IL-3 has an important role in enhancing basophil and mast cell survival. ${ }^{15,32,34-36}$ Interestingly, even though the receptors for IL-5 and GM-CSF share the common $\beta$ chain with the IL-3 receptor, IL-3 seems most potent in enhancing cellular viability and inducing pro-survival BCL-2 family members in basophils and mast cells. ${ }^{18,19,32}$ However, whether and how this increase in specific anti-apoptotic proteins correlates with prolonged basophil and mast cell viability is not fully understood. We recognized that assessing mRNA or protein levels of the distinct BCL-2 family members alone is insufficient to predict relevance without functional readouts, which we performed upon treatment with $\mathrm{BH} 3$ mimetic compounds.

Primarily, we could see that IL-3 rapidly induces the transcription of pro-survival BCL-2 family members (e.g., $\left.B c l-2, M c l-1, B c l-x_{L}\right)$ in mouse basophils and mast cells, which execute important pro-survival functions. We found that IL-3 induces subtly different expression patterns of $\mathrm{BCL}-2$ family genes in basophils compared to mast cells. While $B c l-x_{L}$ was the most strongly induced member in mouse basophils, $\mathrm{Bcl}-2$ induction was more prominent in mast cells. This might indicate that the survival regulation by BCL-2 family members differs in the two cell types. Pro-apoptotic genes (e.g., Puma, caspases) were downregulated in both cell types, further enhancing survival. In mast cells, PUMA has previously been identified as a critical inducer of apoptosis in response to cytokine withdrawal. ${ }^{37}$ Of note, protein levels of the BCL-2 family members altered by IL-3 did not necessarily correlate with mRNA levels, pointing toward regulation of protein stability at the post-translational level. This is well exemplified in the case of MCL-1, which has a short half-life due to fast proteasomal turnover. ${ }^{38}$ Moreover, as already reported in previous studies, BCL-2 as well as MCL-1 might be cleaved by activated caspases. ${ }^{19,39}$

Interestingly, while Bim mRNA levels slightly decreased in IL-3-treated mouse basophils, protein levels increased, indicating post-translational stabilization of BIM (Supplementary Figure S1). In analogy to GM-CSF-treated neutrophils, ${ }^{40}$ increased BIM may serve to limit cytokineinduced survival.

Our study is based on the effects of small molecule $\mathrm{BH} 3$ mimetic compounds, which were developed as anti-cancer therapeutics. ABT-199/ Venetoclax was recently approved by the FDA for aggressive forms of chronic lymphocytic leukemia $(C L L)^{26}$ and numerous clinical trials are ongoing in other cancer entities or using other $\mathrm{BH} 3$ mimetics (reviewed in Opydo-Chanek et al. $^{41}$ ). As $\mathrm{BH} 3$ mimetics show high binding specificities for their pro-survival BCL-2 protein(s), thereby limiting possible side effects, it is conceivable to speculate that those drugs may also be useful in other disease areas. Here, we investigated the functional importance of BCL-2, BCL- $X_{L}$ and MCL-1 in basophil and mast cell survival, and further explored how potently single or combinational inhibition of those proteins could overcome the pro-survival effects of IL-3. The application of $\mathrm{BH} 3$ mimetic compounds benefits from its acute inhibitory effect, thereby avoiding any potential selection or compensatory processes, which might occur upon genetic approaches. ${ }^{42}$ Therefore, our approach reflects the immediate influence of specific loss-of-function of pro-survival proteins on the fate decision of mature basophils and mast cells. It remains possible that our described effects in vitro may not fully reflect the in vivo situation. ${ }^{36}$ However, confirmation in vivo is challenging, in particular in the mouse, due to the tissue residency of mast cells and low frequency of basophils.

Using in vitro-differentiated mouse basophils, ${ }^{27,28}$ we revealed that $B C L-2$ and $B C L-X_{L}$ prevent apoptotic cell death at steady state and identified both BCL-2 and BCL- $X_{L}$ as potential targets to counteract the IL-3-mediated pro-survival effects. Especially the combined inhibition of both proteins by 


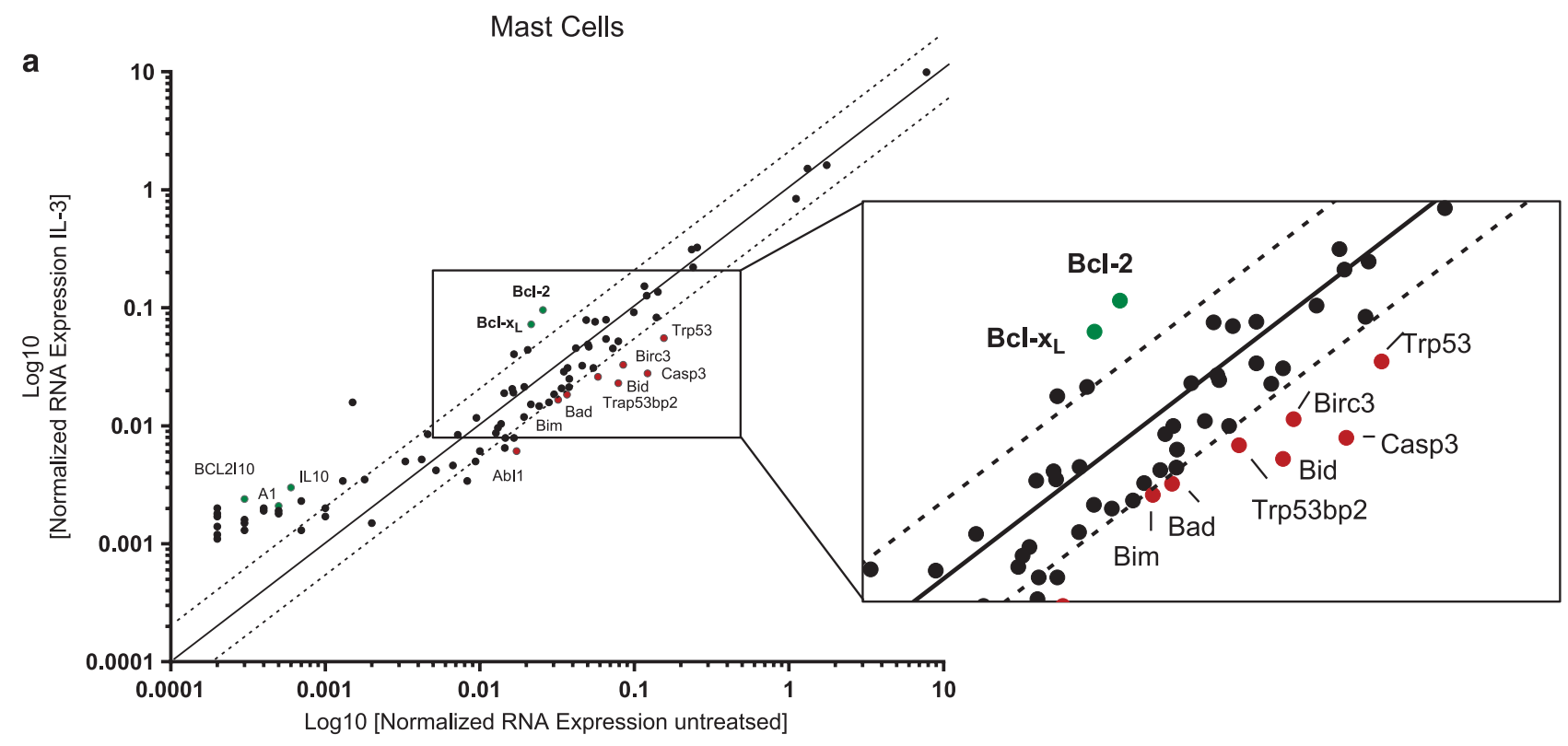

b

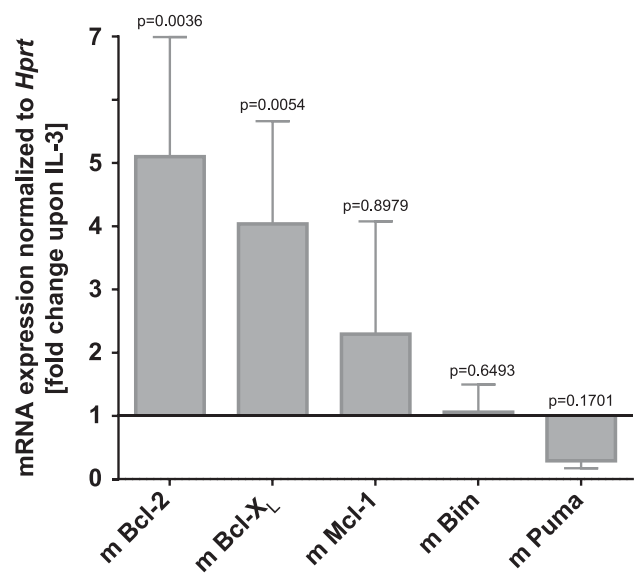

d

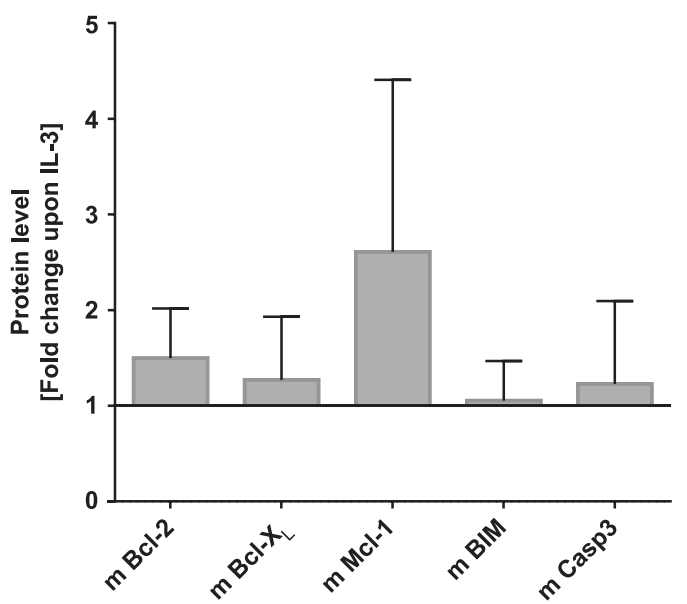

Figure 5 For caption see page on 212

ABT-263 was able to fully neutralize the IL-3 induced survival advantage. Contrarily, and even though MCL-1 also increased upon IL-3 exposure, its functional importance for mouse basophil survival is questioned. Blocking of MCL-1 function by
C

4 hours

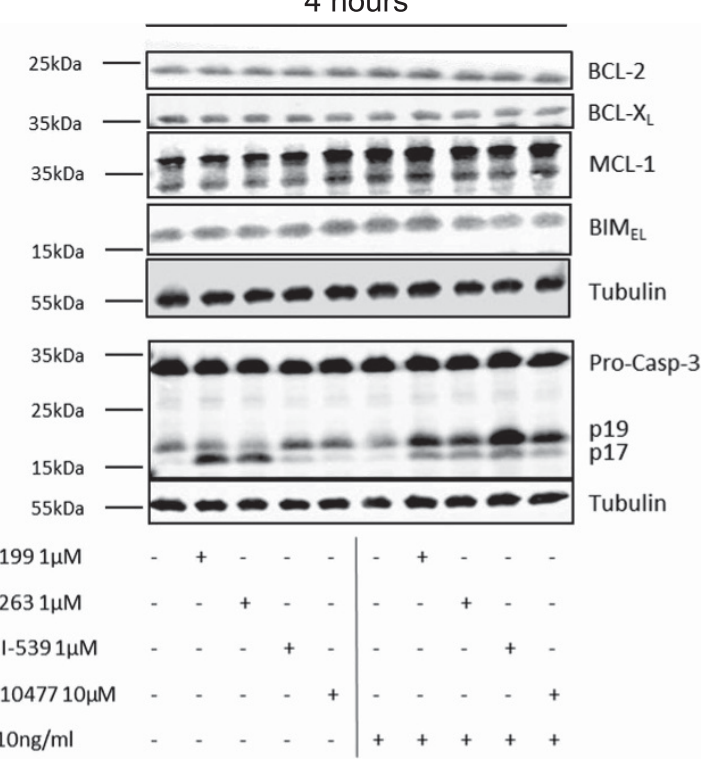

A-1210477 had no significant impact on mouse basophil viability over time and was insufficient to overcome the survival effects of IL-3. Those results suggest that on one hand MCL-1 might have only a minor role in the cell survival regulation and/ 
Figure 5 IL-3-induced transcriptional upregulation of pro-survival BCL-2 family members in mouse mast cells. (a) qPCR array for genes regulated in apoptotic pathways. In vitro-differentiated mouse mast cells (BMMC) were kept either under cytokine-omitted or IL-3 (10 ng/ml)-exposed conditions for $2 \mathrm{~h}$. Using the SA Biosciences software, Ct values were normalized to the average of five different housekeeping genes ( $\beta$ actin, $\beta 2$ microglobulin, Gapdh, Gusb and Hsp90ab1) and linearized with the standard formula for qPCR $\left(2-\left(\mathrm{Ct}^{\text {sample }}-\mathrm{Ct}^{\text {control }}\right)\right)$. While $y$ axis displays the expression of IL-3 treated cells, the $x$ axis shows its corresponding level of untreated cells. Continuous line matches the expression upon IL-3 with the expression of untreated, while dotted lines display a threshold of twofold increase/decrease of the mRNA expression comparing IL-3 over untreated. See complete gene list in Supplementary Table S1. (b) Quantitative RT-PCR (qPCR) analysis of Bcl-2, Bcl- $x_{L}, M c l-1$, Bim and Puma expression upon IL-3-treated relative to cytokine-withdrawn BMMC; $n=3$, means \pm S.D. Statistical analysis was performed by unpaired $t$-test with post hoc Holm-Sidak multiple comparison correction, $P$-values indicated within the graph. (c) Representative quantitative western blots using near-infrared fluorescence of in vitro-differentiated mouse mast cells (BMMC) treated with various $\mathrm{BH} 3$ mimetics at indicated concentrations after IL-3 $(10 \mathrm{ng} / \mathrm{ml})$ conditioning or cytokine withdrawal for $4 \mathrm{~h}(n \geqslant 3)$. (d) Quantitative analysis of western blot data as shown in (c) displayed as fold change upon IL-3 over untreated, normalized to tubulin expression; $n \geqslant 3$, means \pm S.D.

or may be compensated by other pro-survival proteins. Alternatively, MCL-1 might be more important for non-cell death-related functions, such as a previously reported role in the maintenance of mitochondrial integrity and respiration. ${ }^{43}$ Whereas Lilla et al. ${ }^{44}$ have shown that MCL-1 expression is critical for basophil and mast cell development in the mouse, our data suggest that this family member is no longer essential for survival of end-differentiated mouse basophils. On the other hand, we found evidence that BCL-2 and MCL-1 have a critical role in maintaining the integrity of human basophils, while the single inhibition of BCL- $X_{L}$ by WEHI-539 fails to induce significant cell death (Figure 4). Especially the simultaneous administration of A-1210477 with as little as $0.1 \mu \mathrm{M}$ ABT-199 lead to complete human basophil cell death, demonstrating the critical importance of BCL-2 and MCL-1 (Supplementary Figure S3). This suggests that $B C L-X_{L}$ is dispensable for human basophil survival regulation and points toward subtle differences in cell death regulation between mouse and human basophils, which may have important implications with regards to therapeutic applicability, in particular as BCL- $X_{L}$ inhibition in vivo is accompanied by thrombocytopenia.

Mast cells develop from a common myeloid progenitor as basophils in the mouse (reviewed in Sasaki et al. ${ }^{45}$ ). Despite sharing several key features, mast cells and basophils also fulfill distinct immunologic functions. Throughout our study, we were using the well-established model of bone marrowderived c-kit(CD117) ${ }^{+} \mathrm{FccRI}^{+}$mast cells, BMMC (adapted from Kalesnikoff and Galli ${ }^{30}$ and Jensen et al. ${ }^{46}$ ). BMMC do not represent all the different tissue-resident mast cell populations in vivo, but serve as a powerful model to study mast cell function in vitro as well as in vivo. ${ }^{30}$ However, not only bone marrow-derived precursor cells are able to mature into granule filled c-kit(CD117) ${ }^{+} \mathrm{Fc} \varepsilon \mathrm{RI}^{+}$mast cells, but also spleen-derived progenitors are capable to differentiate into mast cells with comparable results as in $\mathrm{BMMC}$ upon $\mathrm{BH} 3$ mimetic treatment (Supplementary Figure S4). This suggests that spleenderived mast cells are a suitable alternative or additive source of in vitro-differentiated mouse mast cells.

Former studies showed that BIM- or PUMA-deficient mast cells are partially resistant to cytokine withdrawal induced cell death in vitro, whereas loss of both PUMA and BIM strongly protect mast cells from apoptosis, to a similar extent seen upon overexpression of BCL-2. ${ }^{37,47,48}$ Our results with ABT-199 confirm the importance of BCL-2 in maintaining mast cell viability and also support previous work that demonstrated the efficacy of ABT-737 (an earlier, ABT-263 related $\mathrm{BH} 3$ mimetic) in killing mouse and human mast cells both in vitro and in vivo. ${ }^{49}$ Furthermore, ABT-199 could partially counteract the potent pro-survival signaling mediated by IL-3. Interestingly, and in contrast to mouse basophils, we found that MCL-1 contributes to BMMC survival and that the IL-3-induced increase in MCL-1 was further contributing to cytokine driven BMMC survival. Similarly, the combined inhibition of BCL-2 and BCL- $X_{L}$ promoted significant apoptosis of BMMC counteracting IL-3-mediated effects. Yet, the inhibition of BCL-2 alone seemed to be sufficient to kill BMMC, suggesting major importance of $B C L-2$ over $B C L-X_{L}$. This finding was further supported by the lack of cell death induction by the BCL- $\mathrm{X}_{\mathrm{L}}$ selective drug WEHI-539. To further substantiate our finding that $B C L-2$ and $M C L-1$ are critically important pro-survival family members for BMMC survival, we could demonstrate that already as little as $0.1 \mu \mathrm{M}$ of ABT-199 leads to a potentiation of the single MCL-1 inhibition (Supplementary Figure S5a).

Whether BH3 mimetic compounds might find their way into a clinical application for basophil and mast cell-driven diseases requires further investigation and needs to be carried on to in vivo models of allergic diseases. In particular, the route of administration (e.g., local versus systemic) and possible side effects caused by loss of other cell types need to be taken into consideration. ${ }^{24}$ Also, the importance of non-apoptotic functions of BCL-2 family members affected by $\mathrm{BH} 3$ mimetics needs to be further assessed, as BCL-2 family members were recognized to be also involved in the regulation of $\mathrm{Ca}^{2+}$ homeostasis, autophagy, non-apoptotic cell death pathways as well as the cell cycle (summarized in Opydo-Chanek et $a .^{41}$ ). In particular, those 'off-target' functions are crucial factors in potential clinical studies deciding on the degree of beneficial outcome and severity of adverse effect on cells and tissues involved in, or independent of, the region of immune reaction.

In summary, we show that there is a notable potential of $\mathrm{BH} 3$ mimetic compounds to kill mouse basophils and mast cells, both in their naive states as well as upon stimulation with a pathophysiologically highly relevant pro-inflammatory cytokine, IL-3, which renders the cells increasingly resistant toward intrinsic apoptosis. We further provide evidence that there are subtle but important differences in how mouse and human basophils, as well as mouse basophils and mast cells, respond to various $\mathrm{BH} 3$ mimetics, respectively. As a consequence, by targeting the right combination of anti-apoptotic BCL-2 family members, it may be possible to selectively eliminate activated basophils or mast cells, respectively, opening interesting possibilities for potential therapeutic 
IL-3
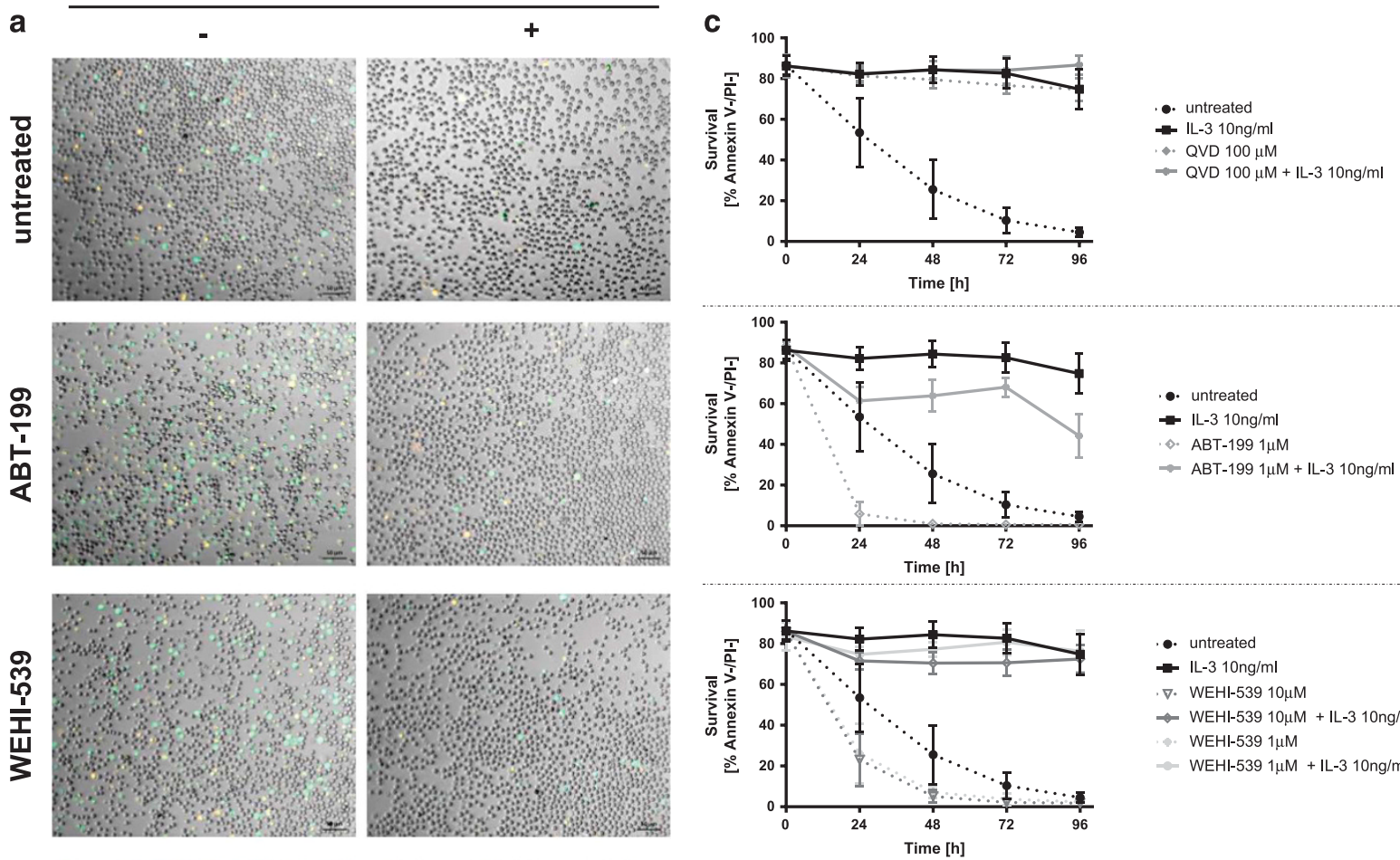

-. untreated

- IL-3 $10 \mathrm{ng} / \mathrm{ml}$

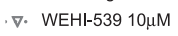

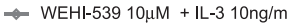

6. WEHI-539 $1 \mu \mathrm{M}$

$=$ WEHI-539 $1 \mu \mathrm{M}+$ IL-3 10ng/ml
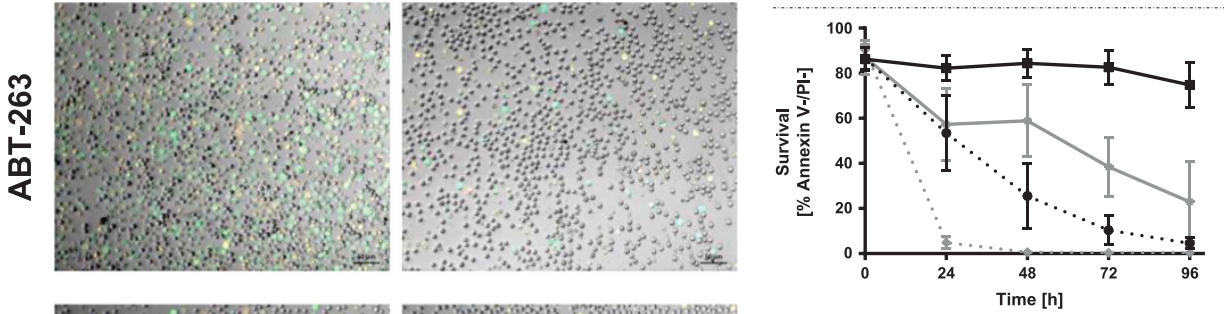

-. untreated

$\Rightarrow \mathrm{IL}-310 \mathrm{ng} / \mathrm{ml}$

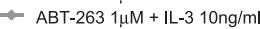
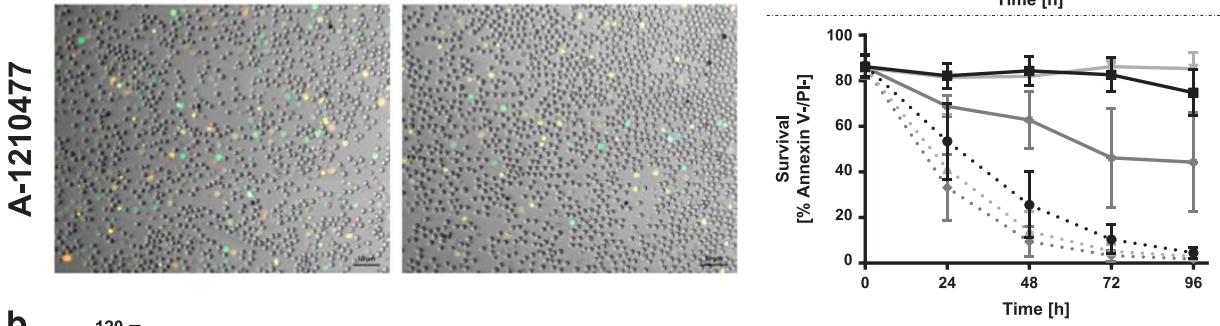

- untreated

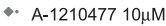

$\rightarrow$ A-1210477 10uM + IL-3 10ng/ml

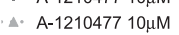

$\rightarrow \mathrm{A}-12104771 \mu \mathrm{M}+\mathrm{IL}-310 \mathrm{ng} / \mathrm{ml}$

b

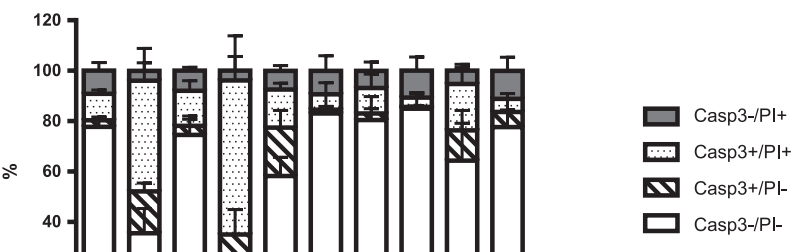

Figure 6 For caption see page on 214 
Figure 6 Viability of mouse mast cells prominently depends on BCL-2 and MCL-1. (a) Enzymatic caspase-3 activity assay (CellEvent) displayed with images of fluorescence microscopy showing active caspase-3 in green, PI positive cells in orange and double-positive in vitro-differentiated mast cells (BMMC) in yellow after $6 \mathrm{~h}$ of treatment with the different BH3 mimetics at indicated concentrations in the presence or absence of IL-3 $(10 \mathrm{ng} / \mathrm{ml})$. Representative pictures are shown ( $n \geqslant 4)$. (b) Quantitative analysis of active caspase-3 and PI staining measured by flow cytometric analysis of same samples shown in (a); $n=4$, means \pm S.D. For statistical analysis, see Supplementary Table S4. (c) Survival of BMMC over time defined as GFP-Annexin V/PI double-negative staining and quantified by flow cytometry after BH3 mimetic treatment at indicated concentrations with or without IL-3 $(10 \mathrm{ng} / \mathrm{ml}) ; n \geqslant 4$ means \pm S.D.

applications for immunological disorders driven by these cell types.

\begin{abstract}
Materials and Methods
Mice and reagents. C57BL/6 mice were maintained under pathogen-free conditions in IVC cages. Animal experiments were approved by the animal experimentation review board of the canton of Bern (BE31/11 and BE12/14).

RPMI-1640 AQmedia, propidium iodide (PI) and Eukitt were purchased from Sigma-Aldrich Chemie GmbH (Buchs, Switzerland). Fetal calf serum (FCS, Sera Pro, ultra-low endotoxin) was purchased from Pan Biotech (Aidenbach, Germany). 2-mercaptoethanol (2-ME), 4-hydroxytamoxifen (4-OHT), and penicillin/streptomycin were from Life Technologies (Carlsbad, CA, USA). WEHI-3B cell-conditioned medium was used as a source of mouse interleukin- 3 and was produced as previously described. ${ }^{27,50}$ Recombinant mouse IL-3 was purchased from Peprotech (London, UK). Q-VD-OPh was purchased from SM Biochemicals (Anaheim, CA, USA). Recombinant $\mathrm{His}^{6}$-tagged GFP-Annexin $\mathrm{V}$ was purified in-house as previously described. ${ }^{51,52}$ Pancoll human (density $1.077 \mathrm{~g} / \mathrm{ml}$ ) was purchased from Pan Biotech, while EasySep Human Basophil Enrichment Kit was bought from StemCell Technologies (Vancouver, Canada). ABT-199 (Venetoclax) was manufactured by BioVision (Milpitas, CA, USA), ABT-263 (Navitoclax) and A-1210477 by Selleck Chemicals (Houston, TX, USA), while WEHI-539 hydrochloride was purchased from Hycultec (Beutelsbach, Germany).
\end{abstract}

Generation of bone marrow-derived mouse mast cells. To generate mast cells, total bone marrow isolated from femurs and pelvises were taken into culture in RPMI-1640 AQmedia (Sigma-Aldrich Chemie GmbH) supplemented with $10 \% \mathrm{FCS}, 1 \%$ penicillin/streptomycin, $50 \mu \mathrm{M}$ 2-mercaptoethanol (2-ME) and $10 \%$ of WEHI-3B cell-conditioned medium as a source of IL-3 $(200 \mathrm{pg} / \mathrm{ml}$ final concentration) (protocol adapted from Swindle ${ }^{53}$ ). After 4 weeks, mast cells were checked for their maturity measuring $\mathrm{CD} 117$ (c-kit) and $\mathrm{Fc} \varepsilon \mathrm{RI}$ surface expression by flow cytometric analysis. In general, the purity of $\mathrm{CD} 117^{+} \mathrm{F} c \varepsilon \mathrm{Rl}^{+}$mast cells within the BMMC culture was between 95 and 99\% (Supplementary Figure S4).

In vitro differentiation of mouse basophils. Conditional Hoxb8 immortalized basophil committed myeloid progenitors, termed IL-3 ${ }^{\text {cond } H o x b 8}$ cells, were generated from bone marrow of WT mice as previously described. ${ }^{27,28}$ Cells were cultured in RPMI-1640 AQmedia supplemented with $10 \%$ FCS, $100 \mathrm{U} / \mathrm{ml}$ penicillin/streptomycin, 10\% WEHI-3B cell-conditioned medium as a source of IL-3 (200 pg/ml final concentration, as determined by ELISA) and $0.1 \mu \mathrm{M} 4-\mathrm{OHT}$. Upon removal of 4-OHT fully mature basophils were generated within 6 days. To confirm the complete differentiation into mature basophils, cells were stained for the surface marker profile $\mathrm{CD} 117 / \mathrm{c}-\mathrm{kit} F \mathrm{C} \varepsilon \mathrm{RI}^{+}$, using the following antibodies (all from BioLegend, San Diego, CA, USA): hamster anti-FceRI (clone MAR-1) and rat anti-CD117 (c-kit, clone 2B8), and measured by flow cytometry (FACS Verse, BD BioSciences, Allschwil, CH) (see Gurzeler et al. ${ }^{27}$ and Reinhart et al. ${ }^{28}$ ). Data were analyzed by FlowJo V.10.1 (Ashland, OR, USA).

Human basophil isolation from human peripheral blood. This study was approved by the local ethical committee (108/14). Upon informed consent of healthy donors, peripheral blood was collected into sterile lithium heparin $\mathrm{BD}$ Vacutainer (BD BioScience) and diluted 1:1 in PBS. This diluted blood was then carefully layered on top of Pancoll human (density $1.077 \mathrm{~g} / \mathrm{ml}$ ) and centrifuged at $800 \times g$ for $20 \mathrm{~min}$. The serum on top of the intermediate phase was aspirated, while the whitish peripheral mononuclear cell (PBMC) population was collected. After two washing steps, basophils were negatively sorted from PBMC fraction using EasySep Human Basophil Enrichment Kit from StemCell Technologies. Following the manufacturer's protocol, $0.75-3 \times 10^{6}$ basophils could be isolated per $100 \mathrm{ml}$ of blood, depending on the donor.
Morphology of both human and mouse basophils and mast cells was analyzed by microscopy (AxioObserver.Z1 fluorescence/light microscope; Zeiss, Oberkochen, Germany) of DiffQuik (Baxter, Deerfield, IL, USA)-stained cytospins (data not shown).

Cell death measurement by flow cytometric analysis. After differentiation of basophils and BMMC, cells were thoroughly washed with PBS prior to incubation with the indicated stimuli, in the presence or absence of high concentrations $(10 \mathrm{ng} / \mathrm{ml})$ of recombinant mouse IL-3. Basophils were stained with GFP-Annexin V diluted in FACS buffer $(150 \mathrm{mM} \mathrm{NaCl}, 4 \mathrm{mM} \mathrm{KCl}, 2.5 \mathrm{mM}$ $\mathrm{CaCl}_{2}, 1 \mathrm{mM} \mathrm{MgSO}_{4}, 15 \mathrm{mM}$ HEPES pH 7.2, 2\% FCS and $10 \mathrm{mM} \mathrm{NaN}_{3}$ ) for $20 \mathrm{~min}$ on ice in the dark. Following one washing step with FACS buffer, cells were resuspended in FACS buffer containing $2 \mu \mathrm{g} / \mathrm{ml}$ of PI and subsequently measured by flow cytometry (FACS Verse, BD BioScience). Data were analyzed using FlowJo version 10.1., where GFP-Annexin V and PI double-negative cells were considered as viable cells and displayed as percentage of overall survival at indicated time points.

Gel electrophoresis and quantitative immunoblotting. After washing with PBS, ca. $3 \times 10^{6}$ cells were directly lysed in pre-heated H8-Buffer $(20 \mathrm{mM}$ Tris/ $/ \mathrm{HCl}$ pH 7.5, 2 mM EGTA, $2 \mathrm{mM}$ EDTA, 1\% SDS, supplemented with 50$100 \mathrm{mM} \mathrm{DTT}$ ) and boiled at $95^{\circ} \mathrm{C}$ for $10 \mathrm{~min}$. The lysates were subsequently homogenized and boiled again for $5 \mathrm{~min}$ after addition of $4 \times$ Lämmli buffer (supplemented with $100 \mathrm{mM}$ DTT). Proteins were separated on 12.5 or $15 \%$ denaturing SDS-PAGE gels and transferred to PVDF membrane (Immobilon-FL, $0.45 \mu \mathrm{M}$, Merck Millipore, Zug, Switzerland). After blocking, the membranes were probed overnight with the following primary antibodies: mouse anti-BCL-2 (clone 10C4, BioLegend); rat anti-BIM (clone 3C5) and rat anti-MCL-1 (clone 19C4); kind gifts from D Huang (Parkville, Victoria, Australia), rabbit polyclonal anti-BCL- $X_{L}$ from Santa Cruz (S-18, Dallas, TX, USA); rabbit polyclonal anti-pro-caspase-3 (\#9662), anti-cleaved-caspase-3 (\#9661) and polyclonal anti-PUMA (\#7467) from Cell Signaling (Danvers, MA, USA); mouse anti-tubulin (clone B-5-1-2) from Sigma Aldrich (St. Louis, MO, USA). For all immunoblots with total lysates, infrared dyeconjugated secondary antibodies (LI-COR Biosciences, Bad Homburg, Germany) were used. All immunoblots were analyzed with the Odyssey Fc Dual-Mode Imaging System using the ImageStudio software 3.1.4 (LI-COR).

Detection of active caspase-3 and -7. Basophils or mast cells of $2-4 \times 10^{5}$ were treated with specified concentrations of $\mathrm{BH} 3$ mimetics for indicated time points. Active caspase- 3 and -7 were stained using CellEvent Caspase-3/7 Green Detection Reagent (Life Technologies, Carlsbad, CA, USA) according to the manufacturer's instructions. Signals were acquired with a Zeiss AxioObserver.Z1 fluorescence microscope using the Zen Blue software (ZEN pro 2012, Zeiss). In addition, cells positive for active caspase-3 and -7 were counted by flow cytometry using the FACS Verse (BD BioScience) and analyzed by FlowJo version 10.1 .

Quantitative PCR and $\mathbf{R T}^{2}$ profiler PCR array. Basophils or mast cells of $3-5 \times 10^{6}$ were incubated for indicated time and compound concentrations, collected, washed twice in PBS and snap-frozen until further procession. mRNA was than isolated using SV Total RNA Isolation System from Promega (Madison, WI, USA). Using all chemicals for the subsequent CDNA production also from Promega, we proceeded by a denaturation and primer annealing step, incubating $1 \mu \mathrm{g}$ total RNA (measured by NanoDrop) per reaction with $0.5 \mu \mathrm{g}$ oligo $\mathrm{d}(\mathrm{T})$ at $70^{\circ}$ $\mathrm{C}$ for 5 min with shock cool on ice. The reverse transcription reaction was than performed by adding $5 \times$ M-MLV reaction buffer, $10 \mathrm{mM}$ dNTP, $25.2 \mathrm{U}$ RNAse inhibitor, $200 \mathrm{U}$ m-MLV RT and nuclease-free water to the before-prepared RNA mix and was incubated for $1 \mathrm{~h}$ at $42{ }^{\circ} \mathrm{C}$ before inactivating the reverse transcriptase at $70^{\circ} \mathrm{C}$ for $10 \mathrm{~min}$. The following $\mathrm{qPCR}$ was completed by $5 \times$ HOT FIREPol EvaGreen qPCR Mix Plus (Solis BioDyne, Tartu, Estonia) using Hprt as reference 
gene for normalization. qPCR was run with Bio-Rad CFX Connect Real-Time System (Hercules, CA, USA). Primers were designed as follows: $m m B c l-2$ fw $5^{\prime}$ tgaagcggtccggtggatac- $3^{\prime}$, rev $5^{\prime}$-ggcggcggcagatgaattac-3'; mmBcl- $x_{L}$ fw $5^{\prime}$-cactgtgc gtggaaagcgta-3', rev $5^{\prime}$-ctcggctgctgcattgttcc-3'; $\mathrm{mmMcl}-1$ fw $5^{\prime}$-ggacgacctataccg ccagt-3', rev 5'-cggagcatgccctggaag-3'; $\mathrm{mmBim}$ fw $5^{\prime}$-gagttgtgacaagtcaac acaaacc-3', rev $5^{\prime}$-gaagataaagcgtaacagttgtaagataacc-3'; mmPuma fw $5^{\prime}$-atgcctgcctc accttcatct-3', rev $5^{\prime}$-agcacaggattcacagtctgga- $3^{\prime}$.

PCR array was purchased from QIAGEN (Venlo, Netherlands). RNA and CDNA were generated as described above and using the same FIREPol EvaGreen qPCR master mix, array was run in CFX Connect cycler with the following program: $15 \mathrm{~min}$ at $95^{\circ} \mathrm{C}$, starting 40 cycles with $15 \mathrm{~s}$ at $95^{\circ} \mathrm{C}, 1 \mathrm{~min}$ at $60^{\circ} \mathrm{C}$ followed by $1 \mathrm{~min}$ at $72{ }^{\circ} \mathrm{C}$ before reading. Data analysis was performed using the supplier's (SA Biosciences, Frederick, MD, USA) PCR array data analysis software and displayed in Prism 6 generated graph.

Statistical analysis. Data from qPCR were statistically analyzed by unpaired $t$-test with post hoc Holm-Sidak for multiple comparison correction, $\alpha=5 \%$. Viability assays over time were statistically analyzed by two-way ANOVA followed by Sidak multiple comparison correction. Significant differences in different population from the CellEvent analysis were analyzed by two-way ANOVA with post hoc test of Turkey's multiple comparison correction, $P$-values are shown in Supplementary Tables S2-S4. All values are represented as means \pm S.D. All statistical analyses were performed using Prism 6 software (GraphPad, La Jolla, CA, USA).

\section{Conflict of Interest}

The authors declare no conflict of interest.

Acknowledgements. We thank Drs D Huang and A Strasser (Parkville, Victoria, Australia) and Dr H-U Simon (Bern, Switzerland) for antibodies and reagents, and Dr Alexander Eggel (Bern, Switzerland) for scientific inputs. This work was supported by the Swiss National Science Foundation (project grant 31003A_149387, to TK) and the Novartis Foundation for medical-biological Research (\#17A014, to TK). RR, SW and LR are or were PhD students of the Graduate School of Cellular and Biomedical Sciences of the University of Bern. Images were acquired on equipment supported by the Microscopy Imaging Centre of the University of Bern.

\section{Author contributions}

RR planned and performed most experiments as well as analyzed data; SW performed experiments. MF, LR and SW provided intellectual inputs and to analyze the data and to revise the manuscript; TK designed the study; RR and TK wrote the paper.

1. Ito $\mathrm{Y}$, Satoh $\mathrm{T}$, Takayama $\mathrm{K}$, Miyagishi $\mathrm{C}$, Walls AF, Yokozeki $\mathrm{H}$. Basophil recruitment and activation in inflammatory skin diseases. Allergy 2011; 66: 1107-1113.

2. Ohnmacht $C$, Voehringer $D$. Basophil effector function and homeostasis during helminth infection. Blood 2009; 113: 2816-2825.

3. Voehringer D. Basophils in immune responses against helminths. Microb Infect 2011; 13: 881-887.

4. Wada $\mathrm{T}$, Ishiwata $\mathrm{K}$, Koseki $\mathrm{H}$, Ishikura $\mathrm{T}$, Ugajin $\mathrm{T}$, Ohnuma $\mathrm{N}$ et al. Selective ablation of basophils in mice reveals their nonredundant role in acquired immunity against ticks. J Clin Invest 2010; 120: 2867-2875.

5. Tsujimura Y, Obata K, Mukai K, Shindou H, Yoshida M, Nishikado H et al. Basophils play a pivotal role in immunoglobulin-G-mediated but not immunoglobulin-E-mediated systemic anaphylaxis. Immunity 2008; 28: 581-589.

6. Wang H, Mobini R, Fang Y, Barrenas F, Zhang H, Xiang Z et al. Allergen challenge of peripheral blood mononuclear cells from patients with seasonal allergic rhinitis increases IL-17RB, which regulates basophil apoptosis and degranulation. Clin Exp Allergy 2010; 40: 1194-1202.

7. Leung DY, Boguniewicz M, Howell MD, Nomura I, Hamid QA. New insights into atopic dermatitis. J Clin Invest 2004; 113: 651-657.

8. Dvorak HF, Hammond ME, Colvin RB, Manseau EJ, Goodwin J. Systemic expression of cutaneous basophil hypersensitivity. J Immunol 1977; 118: 1549-1557.

9. Sokol CL, Medzhitov R. Role of basophils in the initiation of Th2 responses. Curr Opin Immunol 2010; 22: 73-77.

10. Arinobu Y, Iwasaki H, Gurish MF, Mizuno S, Shigematsu H, Ozawa H et al. Developmental checkpoints of the basophi/mast cell lineages in adult murine hematopoiesis. Proc Natl Acad Sci USA 2005; 102: 18105-18110.

11. Blank U, Falcone FH, Nilsson G. The history of mast cell and basophil research - some lessons learnt from the last century. Allergy 2013; 68: 1093-1101.
12. Karasuyama H, Mukai K, Obata K, Tsujimura Y, Wada T. Nonredundant roles of basophils in immunity. Annu Rev Immunol 2011; 29: 45-69.

13. Galli SJ. Mast cells and basophils. Curr Opin Hematol 2000; 7: 32-39.

14. Gibbs BF, Nilsson GP. Basophils unlimited. Allergy 2013; 68: 553-554.

15. Mayer $P$, Valent $P$, Schmidt $G$, Liehl $E$, Bettelheim $P$. The in vivo effects of recombinant human interleukin-3: demonstration of basophil differentiation factor, histamine-producing activity, and priming of GM-CSF-responsive progenitors in nonhuman primates. Blood 1989; 74: 613-621.

16. Valent $P$, Schmidt G, Besemer J, Mayer $P$, Zenke G, Liehl E et al. Interleukin-3 is a differentiation factor for human basophils. Blood 1989; 73: 1763-1769.

17. Shimizu Y, Matsumoto K, Okayama Y, Sakai K, Maeno T, Suga T et al. Interleukin-3 does not affect the differentiation of mast cells derived from human bone marrow progenitors. Immunol Invest 2008; 37: 1-17.

18. Didichenko SA, Spiegl N, Brunner T, Dahinden CA. IL-3 induces a Pim1-dependent antiapoptotic pathway in primary human basophils. Blood 2008; 112: 3949-3958.

19. Hagmann BR, Odermatt A, Kaufmann T, Dahinden CA, Fux M. Balance between IL-3 and type linterferons and their interrelationship with FasL dictates lifespan and effector functions of human basophils. Clin Exp Allergy 2017; 47: 71-84.

20. Souers AJ, Leverson JD, Boghaert ER, Ackler SL, Catron ND, Chen J et al. ABT-199, a potent and selective BCL-2 inhibitor, achieves antitumor activity while sparing platelets. Nat Med 2013; 19: 202-208.

21. Tse C, Shoemaker AR, Adickes J, Anderson MG, Chen J, Jin S et al. ABT-263: a potent and orally bioavailable Bcl-2 family inhibitor. Cancer Res 2008; 68: 3421-3428.

22. Lessene G, Czabotar PE, Sleebs BE, Zobel K, Lowes KN, Adams JM et al. Structure-guided design of a selective BCL-X(L) inhibitor. Nat Chem Biol 2013; 9: 390-397.

23. Leverson JD, Zhang H, Chen J, Tahir SK, Phillips DC, Xue J et al. Potent and selective smallmolecule MCL-1 inhibitors demonstrate on-target cancer cell killing activity as single agents and in combination with ABT-263 (navitoclax). Cell Death Dis 2015; 6: e1590.

24. Fernandez-Marrero Y, Spinner S, Kaufmann T, Jost PJ. Survival control of malignant lymphocytes by anti-apoptotic MCL-1. Leukemia 2016; 30: 2152-2159.

25. Kotschy A, Szlavik Z, Murray J, Davidson J, Maragno AL, Le Toumelin-Braizat G et al. The MCL1 inhibitor S63845 is tolerable and effective in diverse cancer models. Nature 2016; 538 : 477-482.

26. Roberts AW, Davids MS, Pagel JM, Kahl BS, Puvvada SD, Gerecitano JF et al. Targeting BCL2 with Venetoclax in relapsed chronic lymphocytic leukemia. N Engl J Med 2016; 374: 311-322.

27. Gurzeler U, Rabachini T, Dahinden CA, Salmanidis M, Brumatti G, Ekert PG et al. In vitro differentiation of near-unlimited numbers of functional mouse basophils using conditional Hoxb8. Allergy 2013; 68: 604-613.

28. Reinhart R, Wicki S, Kaufmann T. In vitro differentiation of mouse granulocytes. Methods $\mathrm{Mol}$ Biol 2016; 1419: 95-107.

29. Bruncko M, Wang L, Sheppard GS, Phillips DC, Tahir SK, Xue J et al. Structure-guided design of a series of MCL-1 inhibitors with high affinity and selectivity. J Med Chem 2015; 58 : 2180-2194

30. Kalesnikoff J, Galli SJ. Antiinflammatory and immunosuppressive functions of mast cells. Methods Mol Biol 2011; 677: 207-220.

31. Park BS, Kim GC, Back SJ, Kim ND, Kim YS, Kim SK et al. Murine bone marrow-derived mast cells exhibit evidence of both apoptosis and oncosis after IL-3 deprivation. Immunol Invest 2000; 29: 51-60.

32. Zheng X, Karsan A, Duronio V, Chu F, Walker DC, Bai TR et al. Interleukin-3, but not granulocyte-macrophage colony-stimulating factor and interleukin-5, inhibits apoptosis of human basophils through phosphatidylinositol 3-kinase: requirement of NF-kappaBdependent and -independent pathways. Immunology 2002; 107: 306-315.

33. Abraham SN, Arock M. Mast cells and basophils in innate immunity. Semin Immunol 1998; 10: $373-381$.

34. Ohmori K, Luo Y, Jia Y, Nishida J, Wang Z, Bunting KD et al. IL-3 induces basophil expansion in vivo by directing granulocyte-monocyte progenitors to differentiate into basophil lineage-restricted progenitors in the bone marrow and by increasing the number of basophil/ mast cell progenitors in the spleen. J Immunol 2009; 182: 2835-2841.

35. Lantz CS, Boesiger J, Song $\mathrm{CH}$, Mach N, Kobayashi T, Mulligan RC et al. Role for interleukin-3 in mast-cell and basophil development and in immunity to parasites. Nature 1998; 392: 90-93.

36. Shen T, Kim S, Do JS, Wang L, Lantz C, Urban JF et al. T cell-derived IL-3 plays key role in parasite infection-induced basophil production but is dispensable for in vivo basophil survival. Int Immunol 2008; 20: 1201-1209.

37. Ekoff M, Kaufmann T, Engstrom M, Motoyama N, Villunger A, Jonsson Jl et al. The BH3-only protein Puma plays an essential role in cytokine deprivation induced apoptosis of mast cells. Blood 2007; 110: 3209-3217.

38. Adams KW, Cooper GM. Rapid turnover of mcl-1 couples translation to cell survival and apoptosis. J Biol Chem 2007; 282: 6192-6200.

39. Herrant M, Jacquel A, Marchetti S, Belhacene N, Colosetti P, Luciano F et al. Cleavage of Mcl-1 by caspases impaired its ability to counteract Bim-induced apoptosis. Oncogene 2004; 23: 7863-7873.

40. Andina N, Conus S, Schneider EM, Fey MF, Simon HU. Induction of Bim limits cytokinemediated prolonged survival of neutrophils. Cell Death Differ 2009; 16: 1248-1255.

41. Opydo-Chanek M, Gonzalo O, Marzo I. Multifaceted anticancer activity of BH3 mimetics: current evidence and future prospects. Biochem Pharmacol 2017; 136: 12-23. 
42. Mazumder S, Choudhary GS, Al-Harbi S, Almasan A. Mcl-1 phosphorylation defines ABT-737 resistance that can be overcome by increased NOXA expression in leukemic B cells. Cancer Res 2012; 72: 3069-3079.

43. Perciavalle RM, Stewart DP, Koss B, Lynch J, Milasta S, Bathina M et al. Anti-apoptotic MCL-1 localizes to the mitochondrial matrix and couples mitochondrial fusion to respiration. Nat Cell Biol 2012; 14: 575-583.

44. Lilla JN, Chen CC, Mukai K, BenBarak MJ, Franco CB, Kalesnikoff J et al. Reduced mast cell and basophil numbers and function in Cpa3-Cre; Mcl-1fl/fl mice. Blood 2011; 118: 6930-6938.

45. Sasaki H, Kurotaki D, Tamura T. Regulation of basophil and mast cell development by transcription factors. Allergol Int 2016; 65: 127-134.

46. Jensen BM, Swindle EJ, Iwaki S, Gilfillan AM. Generation, isolation, and maintenance of rodent mast cells and mast cell lines. Curr Protoc Immunol 2006; chapter 3:unit 3.23.

47. Alfredsson J, Puthalakath $\mathrm{H}$, Martin $\mathrm{H}$, Strasser A, Nilsson G. Proapoptotic Bcl-2 family member Bim is involved in the control of mast cell survival and is induced together with $\mathrm{Bcl}-$ XL upon IgE-receptor activation. Cell Death Differ 2005; 12: 136-144.

48. Ekoff M, Nilsson G. Mast cell apoptosis and survival. Adv Exp Med Biol 2011; 716: 47-60.

49. Karlberg M, Ekoff M, Huang DC, Mustonen P, Harvima IT, Nilsson G. The BH3-mimetic $\mathrm{ABT}-737$ induces mast cell apoptosis in vitro and in vivo: potential for therapeutics. J Immunol 2010; 185: 2555-2562.

50. Ymer S, Tucker WQ, Sanderson CJ, Hapel AJ, Campbell HD, Young IG. Constitutive synthesis of interleukin-3 by leukaemia cell line WEHI-3B is due to retroviral insertion near the gene. Nature 1985; 317: 255-258.
51. Egger L, Schneider J, Rheme C, Tapernoux M, Hacki J, Borner C. Serine proteases mediate apoptosis-like cell death and phagocytosis under caspase-inhibiting conditions. Cell Death Differ 2003; 10: 1188-1203.

52. Ernst JD, Yang L, Rosales JL, Broaddus VC. Preparation and characterization of an endogenously fluorescent annexin for detection of apoptotic cells. Anal Biochem 1998; 260 : 18-23.

53. Swindle EJ. Generation of mast cells from murine stem cell progenitors. Methods Mol Biol 2014; 1192: 63-67.

(c) (i) (2) (2) This work is licensed under a Creative Commons Attribution-NonCommercial-ShareAlike 4.0 International License. The images or other third party material in this article are included in the article's Creative Commons license, unless indicated otherwise in the credit line; if the material is not included under the Creative Commons license, users will need to obtain permission from the license holder to reproduce the material. To view a copy of this license, visit http://creativecommons.org/licenses/by-nc-sa/4.0/

(C) The Author(s) 2018

Supplementary Information accompanies this paper on Cell Death and Differentiation website (http://www.nature.com/cdd) 